\title{
ASSESMENT OF ACCOMMODATIVE ABILITY IN AVIATION MEDICAL CERTIFICATION STANDARDS
}

\author{
Marcin JEZIERSKI \\ Military Institute of Aviation Medicine, Department of Ophthalmology, Warsaw, Poland
}

Source of support: Own sources

Author's address: M. Jezierski, Military Institute of Aviation Medicine, Department of Ophthalmology, Krasińskiego 54/56 Street, 01-755 Warsaw, Poland, e- mail: jezier@tlen.pl

Background: The author presents mechanical and physiological mechanisms of accommodation of the eye and the effect of age on its efficiency. Standard methods that are used to measure accommodative ability in pilots are also described. Additionally, the paper broadly discusses the importance of adequate accommodative response in terms of aerospace medicine and the safety of flight. Vision qualification requirements applicable to the aviation medical certification standards in Poland and other countries are also presented. The author emphasizes the potential benefits of extended measurements of accommodative ability in pilots during periodic medical examinations.

Keywords: accommodation of the eye, pilots, periodic examinations

\section{INTRODUCTION}

Accommodation is a very important part of the refractive mechanism of the eye that enables the eye to focus on objects at various distances. This process consists in changing the refractive power of the lens, mainly through the change of its shape and location.

Accommodation of the eye is particularly important in pilots who need to quickly change focus from the instrument panel to objects outside the cockpit and vice versa. Accommodative performance is the factor that largely determines the response time to changing flight conditions and impacts the safety of flight. It has been demonstrated that accommodative ability declines with increasing age. This natural and irreversible process varies in each individual case in terms of intensity and dynamics. The analysis of parameters of accommodation can provide valuable information on a pilot's visual performance at a specific point of his/her life. Therefore, medical qualification standards should involve assessment of accommodative ability as one of the aspects of vis-

Figures: 1 - Tables: 2 - References: 20 • Full-text PDF: http://www.pjamp.com • Copyright (C) 2013 Polish Aviation Medicine Society, ul. Krasińskiego 54/56, 01-755 Warsaw, license WIML • Indexation: Index Copernicus, Polish Ministry of Science and Higher Education 
ual performance, since it is very important to the safety of flight.

\section{Anatomical and physiological mechanisms of accommodation}

Accommodation is the process by which the eye changes optical power to maintain focus on an object as its distance varies. As previously mentioned, accommodation is effected by a change in shape and location of the crystalline lens in response to contraction or relaxation of the ciliary muscle [13].

The crystalline lens is a transparent, biconvex, slightly flattened, spheroidal structure in the eye. A circle formed by the outer margin of the lens is called the equator of the lens. The lens lies just behind the iris. It is suspended in position by the zonular fibers from the ciliary body. There is a 0.5$\mathrm{mm}$ free space between the lens and ciliary body called the peri-lenticular space [1].

The refractive power of the lens is approximately 20.00D. The ciliary muscle is the key element of the mechanism of accommodation.

The ciliary muscle receives parasympathetic fibers from the third cranial nerve, also known as the oculomotor nerve. Signals that travel along the motor neurons of cranial nerve III induce contraction of the ciliary muscle. There is also some evidence that ciliary muscle is innervated by sympathetic nerves which are responsible for its relaxation [1].

The most common and widely accepted theory of accommodation was proposed by Hermann von Helmholtz. Helmholtz's theory posits that when viewing a far object, the cliliary muscle relaxes allowing the lens zonules and suspensory ligaments to pull on the lens, flattening it. When an eye focuses on a near object, it accommodates. The ciliary muscle contracts causing the lens zonules to slacken which allows the lens to spring back into a thicker, more convex, form and increase its refractive power.

Accommodation of the eye is a multifactorial process. It depends on external sensory factors, such as the distance between the eye and the object being viewed, and non-sensory factors such as imagination, attention and awareness that we can control to some extent [6].

\section{Parameters for evaluating accommodative ability and their measurement}

Several characteristics can describe accommodative efficiency. The amplitude of accommodation is one of them. The amplitude of accommodation $(A A)$ is determined by the baseline refraction and the near point of vision that is the point near- est the eye at which an object is clearly focused on the retina when accommodation of the eye is at a maximum.

The simplest method to determine this point is the "push-up" method of Donders. A small acuity target, such as letters in printed text, is moved toward the patient's eye(s) until blur is first noted and the distance at which blur is reported is the amplitude of accommodation. However, the "pull away method", in which a target is placed close to the subject and then slowly pulled away until it can be identified, seems to be more reliable. Any refractive error should be corrected with spectacles and if this is the case, the near point of vision is determined relative to the spectacle frame. The amplitude of accommodation can also be measured with a modified autorefractor which must be possible to measure the refractive power of the eye when the subject is looking at objects that are located at different distances from his/her eye $[3,11]$. In such case, the amplitude of accommodation is the difference between the lowest and highest refraction value and is expressed in diopters.

Accommodative response is another useful measure of accommodative efficiency [15]. This parameter measures the accommodative ability of the eye when viewing near-point visual tasks. It can estimate the deficiency or excess of accommodation relative to the distance of the observed object. The accommodative response can be measured clinically by the use of dynamic retinoscopy. The test is performed on each eye separately, with the patient fixating binocularly a near object.

The dexterity of accommmodation is also a function of accommodative ability. It is defined as ability to rapidly change accommodation in response to changes in fixation and is usually measured by the number of cycles of changes in accommodation completed in 1 minute (cpm) [15]. This parameter can be assessed using a near-far alternate fixation technique (distance rock) or the accommodative flipper test (lens rock). The distance rock test is performed by having the subject rapidly change accommodation from a distant target to a near target and report when the image starts to focus. The accommodative flipper is a bar with two pairs of optical lenses of equal and opposite spherical power, e.g. $-2.0 \mathrm{D}$ and $+2.0 \mathrm{D}$. Flipping the lenses while the patient is looking at near objects forces the eyes to re-adjust and is considered to be an accommodative stimulus.

The velocity of accommodation is rarely measured. It is defined as a change in refractive power of the eye over a specified period of time and ex- 
pressed in diopters per second. Standard eye examination does not involve measurement of the speed of accommodation. Currently, there are no commercially available optical devices designed specifically to measure dynamic accommodative performance. Such measurements require estimation of change in refractive power of the crystalline lens and duration of this change. These variables can be determined indirectly using experimental optical systems, by measuring the amount of time needed to change accommodation within a known range or directly by the use of an open-field autorefractor with incorporated timer function. The autorefractor records changes in accommodation that take place over a specified time period and thus determines the speed of accommodation.

\section{Age-related changes in accommodative function}

It is well established that accommodative ability decreases with age. As we get older, the crystalline lens gradually loses the ability to change its shape [14] and, consequently, to change its refractive power $[18,9]$. However, this process is due to a hardening and stiffening of the lens nucleus rather than the lens capsule, since neither elasticity nor other properties of the lens capsule change with age [20]. Age-related increase in size of the lens also seems to be important for deterioration of accommodative ability. Increasing lens thickness is responsible for shortening of the distance between the lens equator and the ciliary body, and shrinkage of the space needed for the lens to freely move during accommodation (according to the Muller's theory of accommodation) [19]. Virtually all of the above described parameters that determine accommodative ability decrease with age. However, reduction in accommodative amplitude (Figure 1) is most bothersome when it leads to significant impairment of the ability to focus on near objects (e.g., reading) that requires spectacle correction. This phenomenon is called presbyopia and usually occurs in most individuals around the age of 40 to 45 years, though high inter-individual variability can be observed.

Between 40 and 45 years of age accommodative response is also impaired, as measured by dynamic retinoscopy. Age-related decrease in accommodative response and accommodative performance indicates the need for near vision correction.

Studies suggest that increasing age has an adverse effect on dynamic accommodation process leading to the loss of amplitude of accommodation and increase in reaction time for the accommodation response $[8,12]$. A study in subjects aged 5-49 years demonstrated that the speed of far-to-near accommodation response (positive accommodation) was about $21.7 \mathrm{D} / \mathrm{s}$ in children and decreased to about $2.0 \mathrm{D} / \mathrm{s}$ in adults, as measured by automated infrared photoretinoscopy. Similarly, the speed of near-to-far accommodation response (negative accommodation or disaccommodation) was $32.7 \mathrm{D} / \mathrm{s}$ in children and only $18.0 \mathrm{D} / \mathrm{s}$ in adults. However, in all subjects near-to-far accommodation was faster than far-to-near accommodation [16]. Though this process is slower than the loss of amplitude of accommodation, it is clearly visible [7] and seems to affect more positive accommodation response time than negative accommodation response time under good light conditions [17]. However, under poor light conditions, the average negative accommodation response time may be 10 -fold longer in subjects aged 50 years and over than in those aged 20 years [5].

Impairment of accommodative ability is a natural part of aging. This process is irreversible, however its dynamics and intensity may significantly differ between individuals. The above described parameters can provide valuable information on a subject's visual performance at a specific point of his/her life.

\section{Assessment of accommodative ability in medical certification standards}

Currently, only civil aviation medical examinations involve assessment of accommodative function in Poland. These examinations are performed in accordance with the President of the Civil Aviation Office's Guidelines No. 3 of 16 July 2012 which are consistent with the Joint Aviation Requirements (JAR) [10]. The JAR are recognized by the Civil Aviation Authorities of participating countries and comprise a series of regulations that cover in details the requirements for aero-medical assessment of cabin crew (JAA Manual of Civil Aviation Medicine). This assessment includes measurement of binocular accommodative amplitude using the Donder's push-up method. The aviation medical certification standards for amplitude of accommodation and near-point of vision are provided in Table 1. The JAR guidelines mention that speed of accommodation decreases with age, but they do not recommend any medical standards or test for assessment of dynamic accommodative performance. This document defines the 'effective accommodation' as the amount of accommodative effort which can be used regularly over a prolonged period of time without causing asthenopia (visual 
fatigue). Figure 1 (adapted from the JAA Manual of Civil Aviation Medicine) illustrates the relationship between the maximum and effective accommodative range.

Tab. 1. The JAR standards (European civil aviation safety requirements) for amplitude of accommodation and near-point of vision by age.

\begin{tabular}{|c|c|c|}
\hline Age & Diopters & Near-point $(\mathbf{c m})$ \\
\hline 16 & $12 \cdot 1$ & $8 \cdot 2$ \\
\hline 18 & $11 \cdot 7$ & $8 \cdot 5$ \\
\hline 20 & $11 \cdot 3$ & $8 \cdot 8$ \\
\hline 22 & $10 \cdot 8$ & $9 \cdot 3$ \\
\hline 24 & $10 \cdot 3$ & $9 \cdot 7$ \\
\hline 26 & $9 \cdot 8$ & $10 \cdot 2$ \\
\hline 28 & $9 \cdot 3$ & $10 \cdot 8$ \\
\hline 30 & $8 \cdot 8$ & $11 \cdot 4$ \\
\hline 32 & $8 \cdot 3$ & $12 \cdot 0$ \\
\hline 34 & $7 \cdot 7$ & $13 \cdot 0$ \\
\hline 36 & $7 \cdot 1$ & $14 \cdot 1$ \\
\hline 38 & $6 \cdot 5$ & $15 \cdot 4$ \\
\hline 40 & $5 \cdot 8$ & $17 \cdot 2$ \\
\hline 42 & $5 \cdot 0$ & $20 \cdot 0$ \\
\hline 44 & $4 \cdot 3$ & $23 \cdot 3$ \\
\hline 46 & $3 \cdot 4$ & $29 \cdot 4$ \\
\hline 48 & $2 \cdot 5$ & $40 \cdot 0$ \\
\hline 50 & $1 \cdot 8$ & $55 \cdot 6$ \\
\hline 52 & $1 \cdot 6$ & $62 \cdot 5$ \\
\hline 54 & $1 \cdot 4$ & $71 \cdot 4$ \\
\hline 56 & $1 \cdot 3$ & $76 \cdot 9$ \\
\hline 60 & $1 \cdot 2$ & $83 \cdot 3$ \\
\hline 65 & $1 \cdot 1$ & $90 \cdot 9$ \\
\hline 70 & $1 \cdot 0$ & $100 \cdot 0$ \\
\hline
\end{tabular}

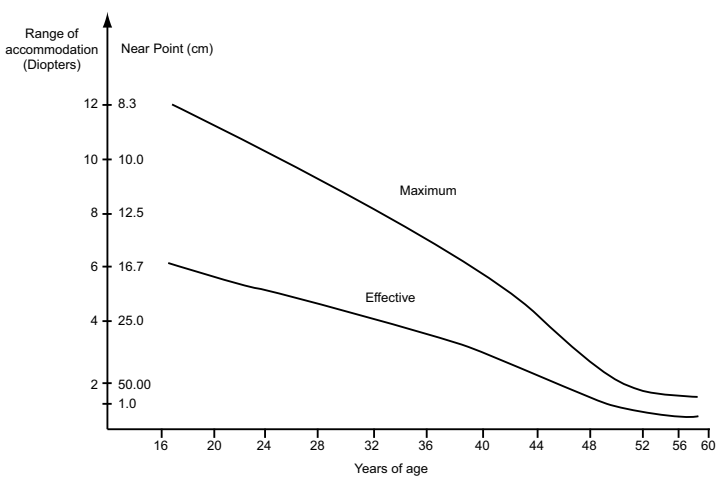

Fig. 1. Maximum and effective accommodative range by age according to the Joint Aviation Requirements (JAR)

In Poland, the aeromedical military certification do not include evaluation of accommodative function of the eye. The Air Force Instruction
48-133 "Medical Examination and Standards" of 1 June 2000 establishes procedures, requirements, recording, and medical standards for medical examinations given by the United States Air Force [2] These standards include measurement of monocular accommodative amplitude using the Donder's push-up method. Accommodation standards according to the age are provided in Table 2.

Available data suggest that military aviation medical requirements do not involve assessment of accommodative function in countries such as Germany, Denmark, Finland or the Czech Republic [4].

\section{SUMMARY}

Assessment of parameters that describe accommodative function seems to be essential due to the importance of accommodation for pilot's visual performance. In particular, it applies to pilots over 40 years of age who sometimes experience significant decrease in accommodative efficiency. Reduced amplitude of accommodation may cause near vision problems. However, instrument panels in traditional cockpits are typically located $80-100 \mathrm{~cm}$ away from the eyes, so the pilot may exert lesser accommodative effort to see them clearly.

In contrast, near vision tasks such as reading (documents, aeronautical charts, approach charts, instructions) require increased accommodative effort due to close working distance $(30-40 \mathrm{~cm})$. Hyperopic pilots need particular attention because sustained accommodative effort necessary to overcome a refractive error may precipitate accommodative dysfunction. Moreover, poor light conditions may further compromise accommodative ability in older pilots and substantially affect safe flight. Therefore, measurement of accommodative amplitude seems to be very important in aircrew officers.

Age-related decrease in speed of accommodative responsiveness is associated with lower perceptual speed and impaired ability to recognize objects at near, intermediate and far distances. Significantly increased reaction time needed to respond to rapidly changing flight conditions may affect the safety of the flight. Measurement of accommodative responsiveness helps the examiner to detect early signs of accommodative dysfunction such as decreased speed of accommodation despite acceptable amplitude of accommodation. This is the case in pre-presbyopes who do not need spectacle correction to cope with near tasks at the moment, but may require it soon. These problems manifest when the effective accommodation becomes insufficient to focus on near ob- 
M. Jezierski - Assesment of Accommodative...

Tab. 2. Accommodation standards according to the Air Force Instruction 48-133 of 1 June 2000.

\begin{tabular}{|c|c|c|c|}
\hline Age & Diopters & Age & Diopters \\
\hline 17 & $8 \cdot 8$ & 32 & $5 \cdot 1$ \\
\hline 18 & $8 \cdot 6$ & 33 & $4 \cdot 9$ \\
\hline 19 & $8 \cdot 4$ & 34 & $4 \cdot 6$ \\
\hline 20 & $8 \cdot 1$ & 35 & $4 \cdot 3$ \\
\hline 21 & $7 \cdot 9$ & 36 & $4 \cdot 0$ \\
\hline 22 & $7 \cdot 7$ & 37 & $3 \cdot 7$ \\
\hline 23 & $7 \cdot 5$ & 38 & $3 \cdot 4$ \\
\hline 24 & $7 \cdot 2$ & 39 & $3 \cdot 1$ \\
\hline 25 & $6 \cdot 9$ & 40 & $2 \cdot 8$ \\
\hline 26 & $6 \cdot 7$ & 41 & $2 \cdot 4$ \\
\hline 27 & $6 \cdot 5$ & 42 & $2 \cdot 0$ \\
\hline 28 & $6 \cdot 2$ & 43 & $1 \cdot 5$ \\
\hline 29 & $6 \cdot 0$ & 44 & $1 \cdot 0$ \\
\hline 30 & $5 \cdot 7$ & 45 & 0.6 \\
\hline 31 & $5 \cdot 4$ & & \\
\hline
\end{tabular}

jects and accommodative reserve has to be used for clear near vision. Considerable and prolonged accommodative effort during flight may cause astenopia or visual fatigue as a result of accommodative inefficiency. This, in turn, may lead to impairment of visual attention and perception of changing environmental conditions. Perception problems may substantially affect pilot's comfort and flying performance, and increase emotional stress. Therefore, measurements of both accommodative amplitude and speed of accommodative response seem to be of particular importance in subjects aged over 40 years.

It is worthy of note that accommodative insufficiency is not only an inevitable consequence of ageing but can also occur in eye conditions such as glaucoma, iritis or scleritis. Sometimes, it is associated with systemic diseases such as diabetes, anemia, sinusitis, Parkinson's disease and multiple sclerosis. Accommodative insufficiency was also reported with drugs like antihistamine agents and other substances such as marijuana or alcohol. However, some drugs may induce excessive accommodative response, and even spasm of accommodation which may prevent normal function of the eye. These medicines include sulphonamides and morphine. Certain medical conditions such as encephalitis, trigeminal neuralgia and injuries of the central nervous system, can also cause similar reaction [15]. Hence, assessment of accommodative function seems to be a reasonable option also in young persons, who may exhibit symptoms of accommodative dysfunction related to the above conditions.
In aircrew officers who were diagnosed with accommodative deficiency, near vision correction should be considered. After all, such correction is unavoidable due to natural deterioration of accommodative ability occurring with age, and may significantly improve comfort and safety of the flight. A practical rule to prevent asthenopia caused by fatigue of accommodation in presbyopic pilots is to use only half of the existing maximum accommodative capacity and prescribe reading glasses for the rest of the necessary accommodative range. This approach is in accordance with current JAR guidelines.

A comprehensive assessment of accommodative ability should constitute an important decision-making factor as a criterion for evaluation of medical fitness for aviation duties. Flight crew members must satisfy increasing requirements determined by continuous technological progress. Thus, aerospace medicine specialists should make any effort to minimize flight safety risks related to human factor. Therefore, it is advisable to devise applicable testing algorithms and relevant standard procedures. The use of available equipment, as well as development of appropriate novel devices should be considered. Laboratory standards for testing static and dynamic parameters of accommodation should also be determined to facilitate assessment of selection and control criteria for flight crew members. 


\section{AUTHORS' DECLARATION:}

Study Design: Marcin Jezierski; Data Collection: Marcin Jezierski; Manuscript Preparation: Marcin Jezierski; Funds Collection: Marcin Jezierski. The Authors declare that there is no conflict of interest.

\section{REFERENCES}

1. Adler, F. (1968) Fizjologia oka. Warszawa: PZWL.

2. Air Force Pamphlet 48-133, 1 JUNE 2000 Aerospace Medicine Physical Examination Techniques [Online]. Available from: http://www.usa-federal-forms.com/us-air-force-forms-pdf-optimized-version-b/afpam48-133.pdf. [Accessed 22.02.2013].

3. Anderson, H.A., Manny, R.E., Glasser, A., Stuebing, K.K. (2011) Static and dynamic measurements of accommodation in individuals with down syndrome. Invest Ophthalmol Vis Sci. 52 (1). 310-17.

4. Bieniek, R., Mikuliszyn, R., Żebrowski, M. (2004) Orzecznicze standardy okulistyczne w wybranych siłach powietrznych świata: implikacje dla Sił Powietrznych R.P. Polski Przegląd Medycyny i Psychologii Lotniczej. 10: 385-90.

5. Elworth, C.L., Larry, C., Malmstrom, F.V. (1986) Age, degraded viewing environments, and the speed of accommodation. Aviat Space Environ Med. 57 (1). 54-8.

6. Francis, E.L., Jiang, B.C., Owens, D.A., Tyrrell, R.A. (2003) Accommodation and vergence require effort-to-see. Optom Vis Sci. 80 (6). 467-73.

7. Heron, G., Charman, W.N., Gray, L.S. (1999) Accommodation responses and ageing. Invest Ophthalmol Vis Sci. 40 (12). 2872-83.

8. Heron, G., Schor, C. (1995) The fluctuations of accommodation and ageing. Ophthalmic Physiol Opt. 15 (5). 445-9.

9. Heys, K.R., Cram, S.L., Truscott, R.J. (2004) Massive increase in the stiffness of the human lens nucleus with age: the basis for presbyopia? Mol Vis. 10. 956-63.

10. JAA Manual of Civil Aviation Medicine. 01.0 2.05 - MANUAL 13 - OPHTHALMOLOGY - 3. Available from: http://www.jaa.nl/ licensing/manual/13\%20-\%200phthalmology.pdf [Accessed 22.02.2013].

11. Mordi, J.A., Ciuffreda, K.J. (2004) Dynamic aspects of accommodation: age and presbyopia. Vision Res. 44 (6). $591-601$.

12. Mrukwa-Kominek, E., Gierek-Ciaciura, S., Wyględowska-Promieńska, D., Zawojska, I. (2003) Ocena zdolności akomodacyjnych układu wzrokowego w zależności od wieku z zastosowaniem systemu WASCA. Klinika Oczna. 105 (5). 277-281.

13. Niżankowska, M. H. (2000) Podstawy okulistyki. Wrocław: Volumed.

14. Pierscionek, B.K. (1995) Age-related response of human lenses to stretching forces. Exp Eye Res. 60 (3). 325-32.

15. Przekoracka-Krawczyk, A., Naskręcki, R. Academy for Eyecare Excellence. Ciba Vision - Materiały konferencyjne. Dysfunkcja akomodacji i metody jej badań. Available from http://www.cibavisionacademy.pl/pdf/20100603.pdf [Accessed 22.02.2013].

16. Schaeffel, F., Wilhelm, H., Zrenner, E. (1993) Inter-individual variability in the dynamics of natural accommodation in humans: relation to age and refractive errors. J Physiol. 461. 301-20.

17. Temme, L.A., Morris, A. (1989) Speed of accommodation and age. Optom Vis Sci. 66 (2). 106-12.

18. Weeber, H.A., Eckert, G., Soergel, F., Meyer, C.H., Pechhold, W., van der Heijde, R.G. (2005) Dynamic mechanical properties of human lenses. Exp Eye Res. 80 (3). 425-34.

19. Zagórski, Z. (2013) Laserowa korekcja presbiopii. CX News nr 1/17/2006; Available from: http://www.cxnews.pl/laserowakorekcja-presbiopii,118.html [Accessed 22.02.2013].

20. Ziebarth, N.M., Borja, D., Arrieta, E., Aly, M., Manns, F., Dortonne, I., Nankivil, D., Jain, R., Parel, J.M. (2008) Role of the lens capsule on the mechanical accommodative response in a lens stretcher. Invest Ophthalmol Vis Sci. 49 (10). 4490-6. doi: 10.1167/iovs.07-1647.

Cite this article as: Janicki A: Three-factor utility function - the safety of pilots levering instrument. Pol J Aviat Med Psychol, 2013; 19(2): 19-24. 